\title{
Pituitary metastases from papillary carcinoma of thyroid: a case report and literature review
}

\author{
Viral Chikani ${ }^{1}$, Duncan Lambie ${ }^{2}$ and Anthony Russell ${ }^{1}$ \\ Departments of ${ }^{1}$ Diabetes and Endocrinology and ${ }^{2}$ Anatomical Pathology, The Princess Alexandra Hospital, \\ 199 Ipswich Road, Woolloongabba, Queensland 4102, Australia
}

Correspondence should be addressed to V Chikani Email

v.chikani@uq.edu.au

\section{Summary}

Metastases to the pituitary gland are an uncommon complication of thyroid cancer. They resemble pituitary neoplasms posing a diagnostic challenge. We present a case of an aggressive non-radioiodine avid papillary thyroid cancer with recurrent pituitary metastases and a review of the literature. A 70-year-old woman with a history of papillary thyroid cancer and bony metastases presented with symptoms of hypoadrenalism and peripheral vision loss. Magnetic resonance imaging showed a large pituitary mass impinging on the optic chiasm. She underwent transsphenoidal resection followed by ${ }^{131}$ I ablation. Post-therapy scintigraphy showed no iodine uptake in the sellar region or bony metastases. Histology of the pituitary mass confirmed metastatic papillary thyroid cancer. Fifteen months later, she had a recurrence of pituitary metastases affecting her vision. This was resected and followed with external beam radiotherapy. Over 2 years, the pituitary metastases increased in size and required two further operations. Radioactive iodine was not considered due to poor response in the past. Progressively, she developed a left-sided III and IV cranial nerve palsy and permanent bitemporal hemianopia. There was a rapid decline in the patient's health with further imaging revealing new lung and bony metastases, and she eventually died 8 months later. To our knowledge, this is the first case of pituitary metastases from a radioiodine-resistant papillary thyroid cancer. Radioiodine-resistant metastatic thyroid cancer may exhibit rapid aggressive growth and remain poorly responsive to the currently available treatment.

\section{Learning points:}

- Differentiated thyroid cancer (DTC) has an excellent prognosis with $<5 \%$ of the cases presenting with distant metastases, usually to lung and bone.

- Metastasis to the pituitary is a rare complication of DTC.

- The diagnosis of pituitary insufficiency secondary to pituitary metastases from DTC may be delayed due to the non-specific systemic symptoms of underlying malignancy and TSH suppression therapy for thyroid cancer.

- The imaging characteristics of metastases to the pituitary may be similar to non-functioning pituitary adenoma.

- Radioiodine refractory metastatic thyroid cancer has significantly lower survival rates compared with radioactive iodine-avid metastases due to limited therapeutic options.

\section{Background}

Pituitary metastases are a rare complication of differentiated thyroid cancer (DTC) (1). Patients often present with symptoms of pituitary insufficiency or symptoms related to mass effects. However, due to the non-specific systemic symptoms of underlying malignancy and TSH suppression therapy for thyroid cancer, the diagnosis of pituitary insufficiency is often delayed. Very little information is available on the imaging characteristics of pituitary metastases.

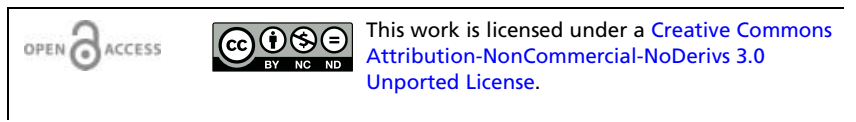


Table 1 Baseline anterior pituitary function tests preoperatively.

\begin{tabular}{l}
\hline Tests (units) \\
\hline GH $(\mu \mathrm{g} / \mathrm{l})$ \\
IGF1 $(\mathrm{nmol} / \mathrm{l})$ \\
FSH $(\mathrm{U} / \mathrm{l})$ \\
LH $(\mathrm{U} / \mathrm{l})$ \\
Oestradiol (pmol/l) \\
Prolactin (mU/l) \\
ACTH (ng/l) \\
Cortisol (nmol/l) \\
TSH (mU/l) \\
Free $\mathrm{T}_{4}(\mathrm{pmol} / \mathrm{l})$ \\
Free tri-iodothyro- \\
nine $\left(\mathrm{T}_{3} ;\right.$ pmol/l) \\
Free alpha glyco- \\
protein subunit \\
(U/l) \\
Short synacthen \\
test: cortisol \\
(nmol/l) \\
Time 0 \\
+30 min \\
+60 min
\end{tabular}

\begin{tabular}{c}
\hline Results \\
\hline 0.2 \\
7 \\
1.2 \\
$<0.2$ \\
33 \\
1660 \\
$<10$ \\
133 \\
$<0.05^{a}$ \\
21 \\
4.8 \\
$<0.1$ \\
\\
\\
\\
\\
\end{tabular}

\begin{tabular}{c}
\hline Reference range \\
\hline$<8.0$ \\
$7-30$ \\
$17-115$ \\
$11-59$ \\
$<100$ \\
$58-416$ \\
$10-50$ \\
$200-700$ \\
$0.3-5.0$ \\
$9-23$ \\
$3.0-5.5$ \\
$<2.0$
\end{tabular}

IGF1, insulin-like growth factor 1 . ${ }^{a}$ During thyroxine $\left(T_{4}\right)$ treatment.

Here, we report a case of pituitary metastases from a radioiodine-resistant papillary thyroid cancer. This case report describes in detail the magnetic resonance imaging (MRI) characteristics and the histopathological findings of pituitary metastases from papillary thyroid cancer and provides an understanding of the natural history and prognosis of this rare disease.

\section{Case presentation, management and outcome}

A 70-year-old woman was under the endocrine unit since 2003 for the management and ongoing surveillance of metastatic papillary thyroid carcinoma. She initially presented in 1988 with a metastatic deposit of follicular variant of a papillary carcinoma of the thyroid in the manubrium that was iodine avid. She underwent a total thyroidectomy with partial resection of the manubrium followed by radioactive iodine ablation. Over a period of 15 years, she received a further five courses of ${ }^{131}$ I ablation, manubriumectomy in 2003 for a relapse of metastatic disease and radiotherapy to T1 vertebral metastases in 2007.

In 2006, during an outpatient visit, she relayed a 12 -week history of $7 \mathrm{~kg}$ weight loss, nausea and vomiting. She was admitted to hospital for investigation of these symptoms, including computerised tomography (CT) of the abdomen, gastroscopy and colonoscopy with no apparent cause found. Subsequently, on resolution of these symptoms after receiving an intra-articular steroid injection for shoulder pain, it was discovered that she was hypocortisolaemic with a morning cortisol of $133 \mathrm{nmol} / \mathrm{l}$ and an abnormal short synacthen test (Table 1). Further investigations revealed mild hyperprolactinaemia and hypogonadotrophic hypogonadism. The TSH had been 'suppressed' from thyroid hormone treatment for metastatic thyroid cancer. Cortisone acetate was commenced with improvement of symptoms. Computerised perimetry showed a superior bitemporal quadrantanopia. MRI of the pituitary (Fig. 1) revealed a $1.5 \mathrm{~cm}$ mass lifting and thinning the optic chiasm with irregular signal intensity on $\mathrm{T} 1$ and mixed intermediate and low T2 signal. She underwent transsphenoidal resection and debulking of the pituitary mass. Histopathology and immunohistochemistry confirmed metastatic papillary thyroid carcinoma of the pituitary gland (Fig. 2A). Following this, she was treated with recombinant TSH and given ${ }^{131}$ I therapy. Unfortunately, her post-therapy scan and single-photon emission computed tomography (SPECT) did not show
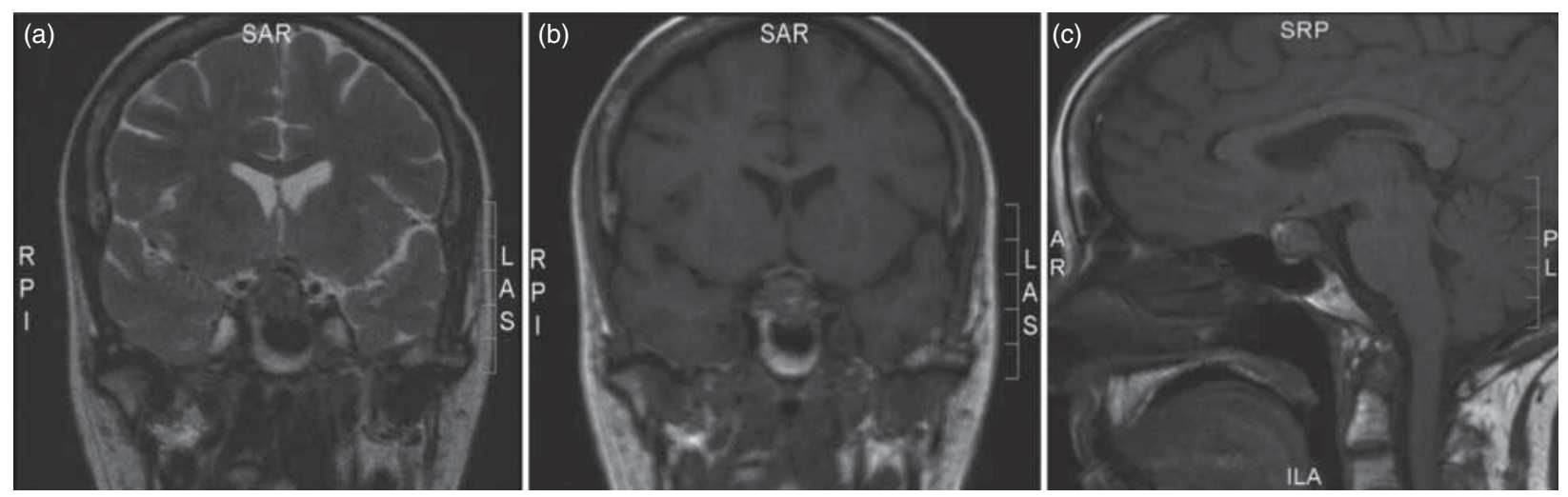

Figure 1

2006 MRI pituitary: (a) coronal T2WI, (b) coronal T1WI and (c) sagittal T1WI respectively. 

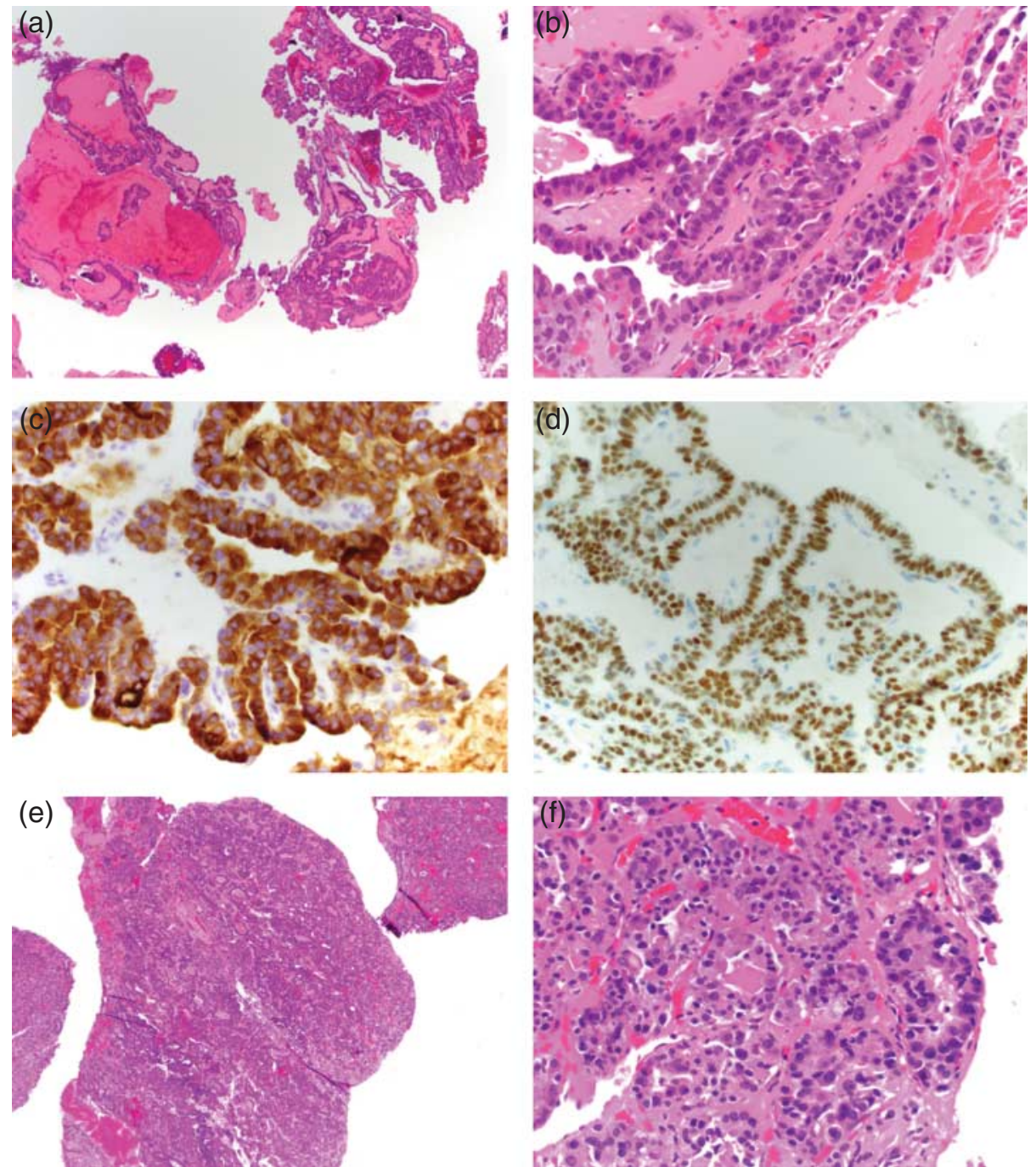

\section{Figure 2}

(Panels a-d) Histopathology of pituitary metastasis at diagnosis:

(a) pituitary metastasis biopsy displaying well-formed papillae and cystic change (H\&E $40 \times$ original magnification); (b) nuclear features of papillary thyroid carcinoma are present including some nuclear overlapping, nuclear grooves and 'dusty' chromatin (H\&E $400 \times$ original magnification);

(c) strong and diffuse reactivity for thyroglobulin $(400 \times$ original

magnification); and (d) diffuse nuclear reactivity for thyroid transcription

any activity in the pituitary fossa region or the thoracic spine, suggesting poor accumulation of iodine and thus ${ }^{131}$ I resistance. Her visual field defects improved following the surgery.

Fifteen months post surgery, she represented with headaches. Repeat computerised perimetry showed worsening bitemporal field defects. Repeat MRI scan of the pituitary (Fig. 3) demonstrated a large $26 \times 30 \times 24 \mathrm{~mm}$ contrast enhancing mass with an irregular border centred within the pituitary fossa and extending into the sphenoid sinus and superiorly to abut and displace the optic chiasm.

factor-1 (400 $\times$ original magnification). (Panels e-f) Histopathology of recurrence in pituitary metastasis 4 years later: (e) it is showing less welldeveloped architecture with cribriform and follicular patterns (H\&E 40X original magnification) and ( $f$ ) it is showing marked variation in nuclear size, hyperchromasia and membrane irregularities (H\&E $400 \times$ original magnification).

She underwent a second transsphenoidal resection and extensive debulking of the tumour, with histology again confirming metastatic papillary thyroid carcinoma. Surgery was followed by $50 \mathrm{~Gy} / 25$ fractions of external beam radiotherapy to the pituitary field. Radioactive iodine was not considered due to lack of previous uptake and to deterioration in her renal function over the last few years.

She failed to achieve an adequate response from her radiotherapy, and over the next 3 years, the pituitary metastasis increased in its supra-sellar extent (Fig. 4). 

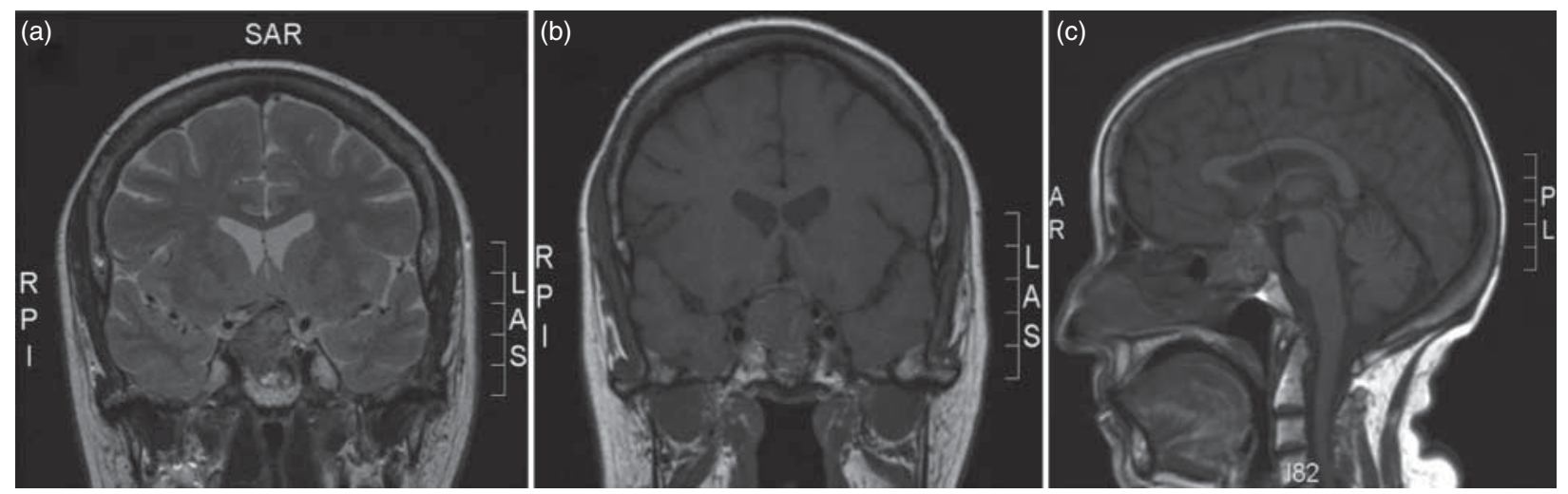

Figure 3

2008 MRI pituitary: (a) coronal T2WI, (b) coronal T1WI and (c) sagittal T1WI respectively.

Computerised perimetry showed variable bitemporal hemianopia, which now crossed the midline and the ocular coherent tomography looking at the retinal nerve fibre layer showed temporal thinning. She underwent a third transsphenoidal debulking of her pituitary metastases, which showed an increase in tumour grading (Fig. 2B). Unfortunately, it markedly increased in size within a couple of months of surgery and the patient developed a left-sided ptosis and further deterioration of vision. In view of her threatened vision, she underwent a fourth debulking of the pituitary metastases, which was performed via transcranial approach. Post surgery, her vision deteriorated further with development of left IV cranial nerve palsy. On restaging imaging, she was found to have new pulmonary and bony metastases. She was assessed for a multicentre, randomised, double-blind, placebo-controlled, phase III trial of a targeted therapy, but she did not meet the criteria due to her poor Eastern Cooperative Oncology Group (ECOG) performance status, recurrent episodes of epistaxis and severe anaemia requiring blood transfusion with high clinical suspicion of occult upper gastrointestinal bleed. There was a progressive decline in vision and physical condition. She died 8 months after her last pituitary surgery.

\section{Discussion}

Pituitary metastases are relatively uncommon, representing $1 \%$ of all sellar neoplasms from surgical and 5\% in autopsy series (1). The most common metastatic malignancies to the pituitary gland are lung in men and breast in women (1). Thyroid cancer is an uncommon cause of pituitary/sellar metastases and, to date, where histological classification has been reported, only four cases of papillary thyroid cancer have been reported (Table 2).

Owing to a high prevalence of pituitary tumours, diagnosis of pituitary metastases can be challenging. Non-specific systemic symptoms (fatigue, nausea and
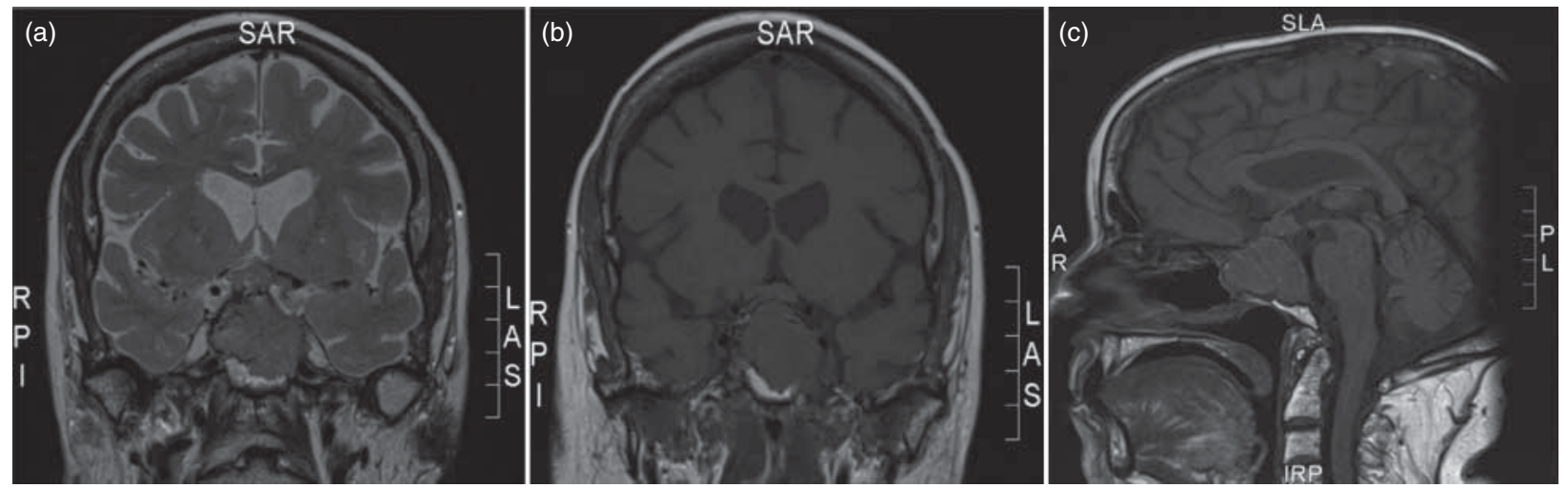

Figure 4

2011 MRI pituitary: (a) coronal T2WI, (b) coronal T1WI and (c) sagittal T1WI respectively. 
Table 2 Characteristics of six published cases of pituitary metastases from papillary thyroid cancer.

\begin{tabular}{|c|c|c|c|c|c|c|}
\hline References & $\begin{array}{l}\text { Clinical } \\
\text { presentation }\end{array}$ & $\begin{array}{l}\text { Other } \\
\text { metastases }\end{array}$ & $\begin{array}{l}\text { Radiological } \\
\text { features }\end{array}$ & $\begin{array}{l}\text { Histological } \\
\text { types }\end{array}$ & Treatment & Outcome \\
\hline (2) & Hypopituitarism & $\begin{array}{l}\text { Lungs, } \\
\text { bones }\end{array}$ & $\begin{array}{l}\text { MRI: } 1.2 \mathrm{~cm} \text { homoge- } \\
\text { neously enhancing } \\
\text { mass }\end{array}$ & Not available & $\begin{array}{l}{ }^{131} \text { I ablation and } \\
\text { chemotherapy }\end{array}$ & $\begin{array}{l}\text { Long-term follow-up } \\
\text { not reported }\end{array}$ \\
\hline (2) & $\begin{array}{l}\text { Diplopia and } \\
\text { ptosis, } \\
\text { hypopituitarism, } \\
\text { vision loss }\end{array}$ & $\begin{array}{l}\text { Lungs, } \\
\text { right } \\
\text { orbit }\end{array}$ & $\begin{array}{l}\text { MRI: large mass invol- } \\
\text { ving cavernous sinus } \\
\text { and pituitary fossa }\end{array}$ & $\begin{array}{l}\text { Papillary thyroid } \\
\text { cancer }\end{array}$ & $\begin{array}{l}\text { Stereotactic radio- } \\
\text { therapy and } \\
{ }^{131} \mathrm{I} \text { ablation }\end{array}$ & $\begin{array}{l}\text { Death within } 12 \\
\text { months of diagno- } \\
\text { sis of pituitary } \\
\text { metastases }\end{array}$ \\
\hline (8) & Hypopituitarism & $\begin{array}{l}\text { Mediastinum, } \\
\text { bone }\end{array}$ & $\begin{array}{l}\text { CT: large intrasellar } \\
\text { pituitary tumour }\end{array}$ & $\begin{array}{l}\text { Papillary thyroid } \\
\text { cancer }\end{array}$ & $\begin{array}{l}\text { Transsphenoidal } \\
\text { surgery and } \\
{ }^{131} \text { | ablation }\end{array}$ & $\begin{array}{l}\text { Died of massive } \\
\text { intrathoracic } \\
\text { haemorrhage }\end{array}$ \\
\hline (9) & $\begin{array}{l}\text { Seizure and visual } \\
\text { disturbance }\end{array}$ & None & MRI: pituitary mass & $\begin{array}{l}\text { Papillary thyroid } \\
\text { cancer }\end{array}$ & $\begin{array}{l}\text { Resection followed } \\
\text { by }{ }^{131} \text { I ablation }\end{array}$ & $\begin{array}{l}\text { At 3-year follow-up, } \\
\text { no evidence of } \\
\text { recurrence }\end{array}$ \\
\hline (10) & $\begin{array}{l}\text { Visual disturbance, } \\
\text { cranial nerve III, } \\
\text { IV and V palsy }\end{array}$ & None & $\begin{array}{l}\text { Skull radiograph: } \\
\text { destruction of the } \\
\text { floor of sella turcica }\end{array}$ & Not available & $\begin{array}{l}\text { Radiotherapy and } \\
{ }^{131} \mathrm{I} \text { ablation }\end{array}$ & $\begin{array}{l}\text { At } 20 \text { months of } \\
\text { follow-up, patient } \\
\text { remained stable }\end{array}$ \\
\hline (4) & $\begin{array}{l}\text { Hemianopsia, } \\
\text { diabetes insipidus, } \\
\text { amenorrhoea }\end{array}$ & Lung & Not available & $\begin{array}{l}\text { Papillary thyroid } \\
\text { cancer }\end{array}$ & $\begin{array}{l}\text { Transsphenoidal } \\
\text { surgery }\end{array}$ & $\begin{array}{l}\text { Long-term follow-up } \\
\text { not reported }\end{array}$ \\
\hline
\end{tabular}

weight loss) of underlying malignancy and TSH suppression therapy in case of thyroid cancer often delay the diagnosis of hypopituitarism caused by pituitary metastases (2).

High-resolution CT and MRI are sensitive imaging modalities but lack specificity. The MRI of pituitary metastases demonstrates an iso-intense or hypo-intense mass on T1 with a hyper-intense signal on T2-weighted image (1). Mayr et al. (3) reported that seven of nine pituitary metastases were iso-intense on both T1- and T2weighted images. Of six published cases of papillary thyroid cancer metastatic to pituitary, only three underwent MRI pituitary; however, detailed descriptions of signal characteristics are not available (see Table 1). MRI of pituitary in our patient revealed a mixed signal in both T1- and T2-weighted images.

Rapid aggressive tumour growth and infiltration of adjacent tissues favour the diagnosis of pituitary metastases. Pituitary metastases from thyroid cancer usually present with symptoms of mass effects like headache, visual loss or signs of other cranial nerve palsy due to supra-sellar extension with optic chiasm compression or cavernous sinus invasion respectively.

Owing to the direct arterial supply, metastases to the posterior lobe of the pituitary gland are more common. The most common symptom reported in the literature is diabetes insipidus in up to $45 \%$ of the cases (1). The incidence of diabetes insipidus in DTC seems much lower and so far only one conclusive case has been reported (4).
The overall 10-year disease-specific survival in DTC is $85 \%$ and it drops to $30-55 \%$ in radioactive iodine-avid metastases and 10-18\% in non-radioactive iodine-avid metastatic disease (5). Standard treatment for DTC includes surgery, radioactive iodine and TSH suppression therapy. When thyroid cancers lose differentiated phenotype, they may not uptake the radioiodine and become ${ }^{131}$ I resistant. Radioiodine refractory metastatic thyroid cancer can be managed with thyroid hormone suppression therapy, external beam radiotherapy or chemotherapy (6). However, cytotoxic chemotherapy for metastatic thyroid cancer has a very limited role due to a poor response rate and significant side effects. The most studied chemotherapeutic agent is doxorubicin, which is used alone or in combination with cisplatin. Less than $25 \%$ of patients with DTC respond to standard chemotherapy and achieve only a partial response lasting no more than a few months (6).

Currently, there are a number of trials underway evaluating the role of therapies targeting specific molecules involved in the molecular and cellular pathogenesis of thyroid cancer. These therapies mainly target angiogenesis, tumour cell growth and apoptotic pathways, and oncogenic signalling pathways (6). In preliminary trials, partial responses are reported in $\sim 15-30 \%$ of patients and none of them has shown complete response.

The role of various redifferentiating agents enhancing iodine uptake by modulating thyroid gene expression to improve the efficacy of ${ }^{131} \mathrm{I}$ ablation in non-radioiodine 
avid tumours has been well described in the literature and results from in vitro studies are promising; however, further studies are needed (7).

In conclusion, pituitary metastases are a rare complication of metastatic DTC. These metastases are aggressive, invasive and large, causing mass symptoms and profound hypopituitarism. These secondary malignancies, when no longer iodine avid, pose a very poor prognosis. The efficacy of other treatment options including external irradiation and chemotherapy is low. Targeted therapies may hold promise to deliver better outcomes for non-radioiodine avid metastatic thyroid disease.

\section{Declaration of interest}

The authors declare that there is no conflict of interest that could be perceived as prejudicing the impartiality of the research reported.

\section{Funding}

This research did not receive any specific grant from any funding agency in the public, commercial or not-for-profit sector.

\section{Patient consent}

The consent form has not been obtained because the patient is dead and the information provided in this report is unidentifiable.

\section{Author contribution statement}

$\checkmark$ Chikani was involved in the patient's care as a registrar and he prepared the manuscript and reviewed the literature. D Lambie reported the histopathology slides. A Russell was the physician responsible for the patient and he reviewed and edited the manuscript.

\section{References}

1 Komninos J, Vlassopoulou V, Protopapa D, Korfias S, Kontogeorgos G, Sakas DE \& Thalassinos NC 2004 Tumors metastatic to the pituitary gland: case report and literature review. Journal of Clinical Endocrinology and Metabolism 89 574-580. (doi:10.1210/jc.2003030395)

2 Masiukiewicz US, Nakchbandi IA, Stewart AF \& Inzucchi SE 1999 Papillary thyroid carcinoma metastatic to the pituitary gland. Thyroid $\mathbf{9}$ 1023-1027. (doi:10.1089/thy.1999.9.1023)

3 Mayr NA, Yuh WT, Muhonen MG, Koci TM, Tali ET, Nguyen HD, Bergman RA \& Jinkins JR 1993 Pituitary metastases: MR findings. Journal of Computer Assisted Tomography 17 432-437. (doi:10.1097/ 00004728-199305000-00018)

4 Bell CD, Kovacs K, Horvath E, Smythe H \& Asa S 2001 Papillary carcinoma of thyroid metastatic to the pituitary gland. Archives of Pathology \& Laboratory Medicine 125 935-938.

5 O'Neill CJ, Oucharek J, Learoyd D \& Sidhu SB 2010 Standard and emerging therapies for metastatic differentiated thyroid cancer. Oncologist 15 146-156. (doi:10.1634/theoncologist.2009-0190)

6 Cooper DS, Doherty GM, Haugen BR, Kloos RT, Lee SL, Mandel SJ, Mazzaferri EL, McIver B, Pacini F et al 2009 Revised American Thyroid Association management guidelines for patients with thyroid nodules and differentiated thyroid cancer. Thyroid 19 1167-1214. (doi:10.1089/ thy.2009.0110)

7 Seregni E, Vellani C, Castellani MR, Maccauro M, Pallotti F, Scaramellini G, Guzzo M \& Greco A 2009 Redifferentiating agents in non-radioiodine avid cancer. Quarterly Journal of Nuclear Medicine and Molecular Imaging 53 513-519.

8 Sziklas JJ, Mathews J, Spencer RP, Rosenberg RJ, Ergin MT \& Bower BF 1985 Thyroid carcinoma metastatic to pituitary. Journal of Nuclear Medicine 261097.

9 Simmons JD, Pinson TW, Donnellan KA, Harbarger CF, Pitman KT \& Griswold R 2010 A rare case of a $1.5 \mathrm{~mm}$ papillary microcarcinoma of the thyroid presenting with pituitary metastasis. American Surgeon $\mathbf{7 6}$ 336-338.

10 Johnson PM \& Atkins HL 1965 Functioning metastasis of thyroid carcinoma in the sella turcica. Journal of Clinical Endocrinology and Metabolism 25 1126-1130. (doi:10.1210/jcem-25-8-1126)

Received in final form 29 May 2013

Accepted 22 July 2013 